\title{
Rastlinske ose iz rodu listaric (Strongylogaster) so poškodovale lubje rdečega bora
}

\author{
Maarten de Groot ${ }^{1 *}$, Boštjan Šneberger ${ }^{2}, Z_{\text {Zoran } Z_{\text {Zvrtanik }}^{3} \text {, Andreja Kavčič }}^{1}$
}

17. marca 2015 smo prejeli obvestilo o poškodovanem rdečem boru (Pinus sylvestris L.) v Ribčah pri Litiji. Skorja drevesa je izrazito odstopala, drevo pa je imelo tudi redko krošnjo. Prizadeto drevo je bilo v sestoju rdečega bora, v bližini katerega se nahaja sestoj smreke (Picea abies). Po pregledu smo na drevesu ugotovili prisotnost več vrst žuželk. Kot glavna povzročitelja poškodb drevesa smo ugotovili modrega borovega krasnika (Coleoptera: Buprestidae, Phaenops cyanea (Fabricius, 1775)) in malega borovega strženarja (Coleoptera: Scolytidae, Tomicus minor (Linnaeus, 1758)). Osebki teh dveh vrst z vrtanjem rovov v živi del drevesne skorje in $\mathrm{v}$ les poškodujejo drevo, kar vodi v zmanjšano odpornost in propad drevesa. Smo pa med rovnimi sistemi, ki so značilni za ti dve vrsti, opazili tudi rovni sistem, ki ga doslej nismo poznali (slika 1), izdelan pa je bil v mrtvem delu lubja. Rov se je začel z razširjenim delom, kamrico, iz katerega so izhajali rovi, ki so se nadalje razvejali $v$ nove rove.

Enak rovni sistem smo kasneje (20. maja 2015) opazili še v Tolminu, prav tako na rdečem boru (sliki 2, 3). Za razliko od drevesa $v$ Ribčah pri Litiji, ki je bilo izrazito oslabljeno, pa je bilo drevo v Tolminu na videz vitalno in ob pregledu ni kazalo znakov oslabelosti (slika 4). Drevo v Tolminu se nahaja v primestnem območju in stoji samo, brez povezave z bližnjimi gozdnimi sestoji.

Po posvetovanju s švedskim strokovnjakom za entomofavno, dr. Åkejem Lindelöwom, smo ugotovili, da najdeni rovni sistem pripada vrsti rastlinskih os iz rodu Strongylogaster.

Vrste iz rodu Strongylogaster uvrščamo med rastlinske ose (Hymenoptera: Symphyta), in sicer v družino listaric (Tenthredinidae). V Evropi je prisotnih šest vrst tega rodu. od katerih sta za Slovenijo znani dve. V zbirki Prirodoslovnega muzeja Slovenije so primerki vrst $S$. filicis (Klug 1817) in S. multifasciata (Geoffrey 1785), ki sta jih nabrala dr. Jaeger in dr. Hafner v obdobju 19331937 (Milivojević in sod., 2009). Kasneje se je s to skupino žuželk ukvarjal dddr. Jože Maček, ki je strokovnjak za vrste, ki so minerji na rastlinah, vendar pa v Sloveniji ni našel nobene vrste iz rodu Strongylogaster (Maček 1999). Glede na to, da je bila prisotnost drugih vrst tega rodu, točneje vrst S. xanthocera (Stephens 1835), S. mixta (Klug 1817) in S. makula (Klug 1817), potrjena v več sosednjih državah (Fauna Europaea, 2013), pričakujemo, da bodo v prihodnosti na našem ozemlju našli tudi te vrste.
Osebki vrst iz rodu Strongylogaster preživijo zimo v lubju borovih dreves v stadiju bube, ki se zgodaj spomladi levi v odraslo obliko. Odrasli osebki so kratkoživi, obdobje njihovega izletanja pa traja od konca aprila do sredine junija (Macek, 2010). Po parjenju samice odložijo jajčeca na liste praproti. Stadij ličinke, ki se razvije iz jajčeca, vključuje pet faz (Welke, 1959). Glavno gostiteljsko rastlino ličink predstavlja orlova praprot (Pteridium aquilinum), vendar se ličinke različnih vrst prehranjujejo tudi z vrstami iz rodov Dryopteris (D. carthusiana, D. dilatata), Athyrium (A. filix-femina) in Polystichum (Taeger et al., 1998). Ličinke zadnjega stadija migrirajo v lubje borov (Pinus spp.) (Schwenke, 1982), kjer izvrtajo rove v odmrli del skorje in se zabubijo brez kokona. Posamezni rov lahko naseljuje več ličink, zato so rovi razmeroma široki. Osebki lahko preživijo v stadiju ličinke tudi dve leti in več.

$Z$ vidika varstva rastlin ose iz rodu Strongylogaster ne predstavljajo nevarnosti za drevo, saj rovni sistem izdelajo $\mathrm{v}$ lubju in tako neposredno ne vplivajo niti na prevajalne elemente niti na druge žive dele drevesa.

\section{Zahvala}

Zahvaljujemo se dr. Åkeju Lindelöwu za pomoč pri identifikaciji rovnega sistema.

\section{Viri}

Fauna Europaea. 2013. http://www.faunaeur.org/ (28.maj.2015)

Maček, J. 2010. Taxonomy, distribution and biology of selected European Dinax, Strongylogaster and Taxonus species (Hymenoptera: Symphyta). Acta Entomologica Musei Nationalis Pragae, 50, 1: 253-271

Maček, J. 1999. Hiponomološka favna Slovenije. Ljubljana, Slovenska akademija znanosti in umetnosti: 385 str.

Milivojević T., Trilar T. Nikolić Z. 2009. Sawflies (Hymentoptera: Symphyta) in the collections of the Slovenian Museum of Natural History. Acta Entomologica Slovenica, 17, 1: 45-72

Schwenke W. 1982. Die Forstschädlinge Europas: 4. Hautflugler un zweiflugler. Hamburg, Verlag Paul Parey: 392 str.

Taeger A., Altenhofer E., Blank S.M., Jansen E., Kraus M., PschornWalcher H., Ritzau C. 1998. Kommentare zur Biologie, Verbreitung und Gefahrdung der Pflanzenwespen Deutschlands (Hymenoptera, Symphyta). V: A. Taeger and S. M. Blank (ur.). Pflanzenwespen Deutschlands (Hymenoptera, Symphyta). Keltern, Verlag Goecke \& Evers: 49-135

Welke G. 1959. Zur Kenntnis von Strongylogaster xanthoceros (Steph.) und Strongylogaster lineata (Christ) und ihrer Parasiten. Beiträge zur Entomologie, 9, 3/4: 234-292

${ }^{1}$ Gozdarski inštitut Slovenije, Večna pot 2, 1000 Ljubljana; 2 Zavod za gozdove Slovenije, OE Ljubljana, KE Domžale, Ljubljanski cesta 72a, 1230 Domžale; 3Zavod za gozdove Slovenije, OE Tolmin, Tumov drevored 17, 5220 Tolmin *maarten.degroot@gozdis.si 


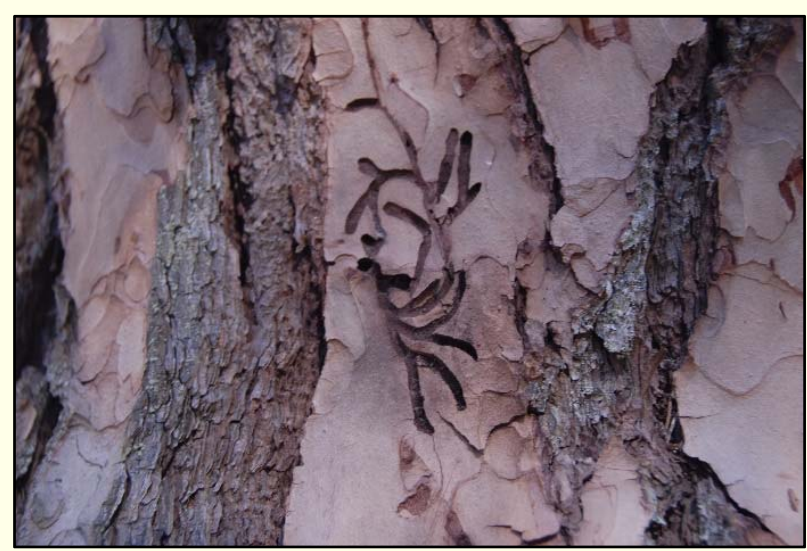

Slika 1: Rovni sistem rastlinske ose iz rodu Strongylogaster na rdečem boru v Ribčah (foto: Maarten de Groot)

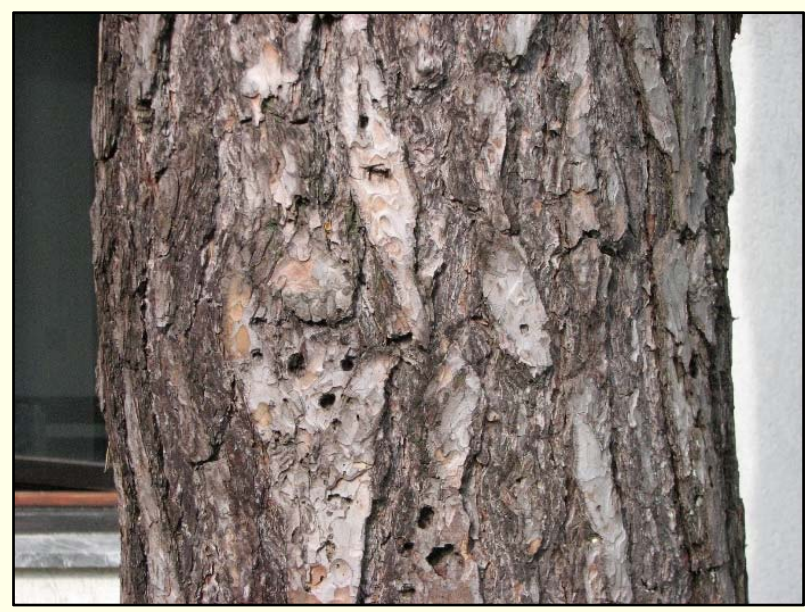

Slika 3: Izhodne luknje odraslih osebkov rastlinske ose iz rodu Strongylogaster na rdečem boru v Tolminu (foto: Zoran Zavrtanik)

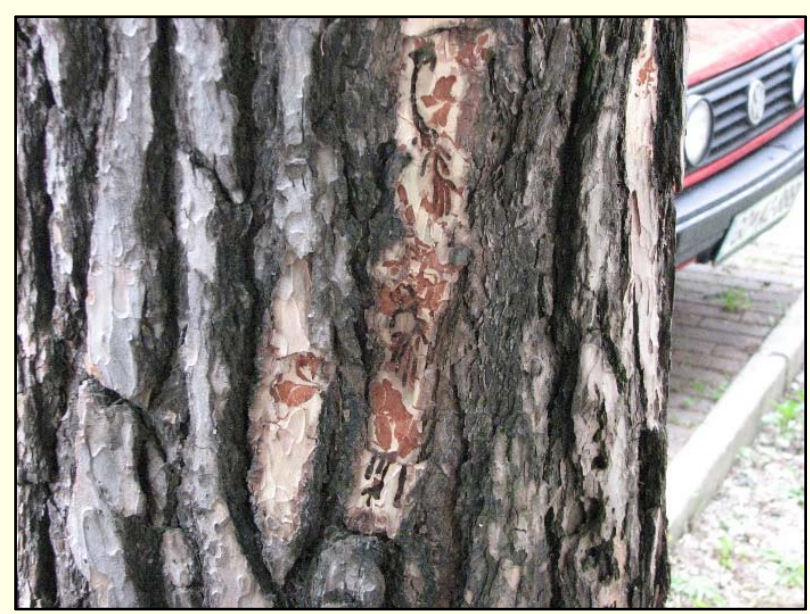

Slika 2: Rovni sistem rastlinske ose iz rodu Strongylogaster na rdečem boru v Tolminu (foto: Zoran Zavrtanik)

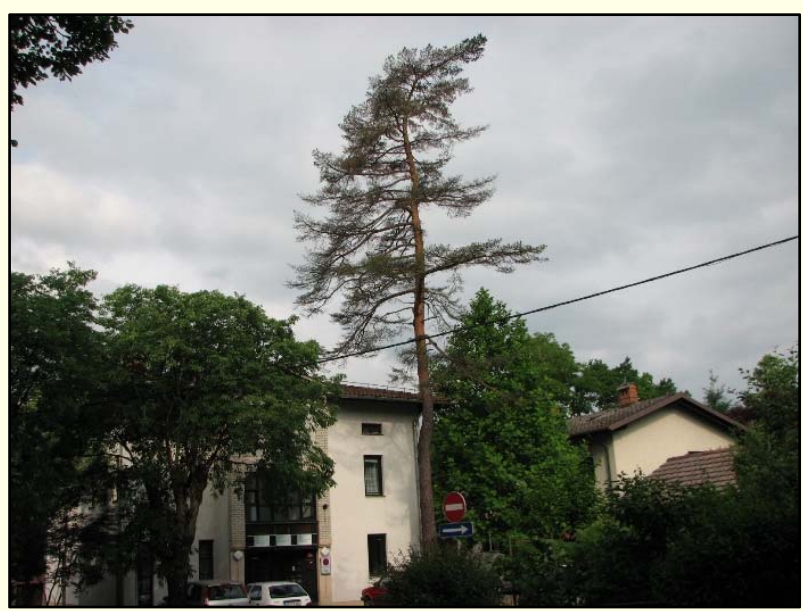

Slika 4: Rdeči bor v Tolminu v katerem smo našli rovni sistem rastlinske ose iz rodu Strongylogaster (foto: Zoran Zavrtanik) 